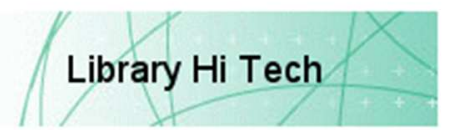

\title{
Experts as Facilitators for the Implementation of Social Media in the Library? A Social Network Approach
}

\begin{tabular}{|r|l|}
\hline Journal: & Library Hi Tech \\
\hline Manuscript ID: & LHT-02-2014-0015.R1 \\
\hline Manuscript Type: & Original Article \\
\hline Keywords: & $\begin{array}{l}\text { Social sciences, Digital libraries, Libraries, Methodology, Skills } \\
\text { Development, Qualitative methods }\end{array}$ \\
\hline \multicolumn{2}{|l}{} \\
\hline
\end{tabular}




\section{Experts as Facilitators for the Implementation of Social Media in the Library? A Social Network Approach}

\section{Introduction}

Digital activities such as engaging in online communities, social networking, and usergenerated content (UGC) production are a growing part of many people's private and professional lives. Social media is the unifying term for these kinds of "new digital media phenomena (...) in which ordinary users (i.e. not only media professionals) can communicate with each other and create and share content with others online through their personal networked computers and digital mobile devices” (Bechmann and Lomborg, 2012, 767).

Since public libraries have always connected people with information, social media urge them to reconsider their position as public knowledge providers (Anttiroiko and Savolainen, 2007). As a modern librarian's task is to be able to use and distribute information in many formats other than print, he or she must be able to use all media, including digital and social media. Similarly, librarians are also increasingly responsible for bridging the gap between social media and end-users to enable the end-users to effectively and efficiently use these media sources (Callahan, 1991). In this context, the debate of media literacy comes at stake, and given our specific focus, we term this as 'social media literacy' (SML). SML can be defined as not only the practical and critically cognitive competencies possessed by users of social media, but also the motivation to employ these media effectively and appropriately for social interaction and communication on the web (Authors, 2013). To accomplish such knowledge provision, librarians must be proficient with social media use.

Although much literature already exists concerning social media use in a library context - mostly referred to as library 2.0 (Casey and Sevastinuk, 2006), it is still in its infancy (Anttiroiko and Savolainen, 2011). Thus far, most of the existing literature focuses on 
the potential use of social media in the library, 'how-to guides' for libraries to implement social media (Linh, 2008), and about competencies of which librarians perceived they need them (Huvila et al., 2013). Empirical data on social media implementation in libraries is rare. Therefore, this paper contributes to this under-researched field by inquiring the actual implementation of social media in libraries, and with a specific focus on the development of SML of librarians.

The functioning of organizations such as libraries is built upon social processes, or relations and interactions, between the employees (Tichy et al., 1979). As such, libraries start using new technologies, such as social media, through localized social processes (Valente, 1996). Actual implementation and use of a new technology within the library depends on the individual members of the organization and the relations and interactions between them. Rogers (1995) and Haythornthwaite (2005) present social network theory and analysis to involve these social processes into the diffusion of innovation research. The social network approach posits that social interactions may have an impact on people's knowledge development about a new technology, which leads to awareness, and consequently has an impact on the implementation (or rejection) of that technology. Moreover, Frambach and Schillewaert (2002) and Haythornthwaite (1996) indicate that information about an innovation is mostly introduced by experts who have the most knowledge, skills, or expertise within the organization and often work on or near the core of the innovation within the organization.

Therefore, the aim of this study is to empirically assess how a social media expert, or the employee with the most knowledge and skills concerning social media, in the library facilitates, or impedes, the information flow and implementation of social media in the library. Thus far, empirical studies on the implementation of innovations within organizations were mainly conducted in the health care industry (e.g. Atun et al., 2007; Williams, 2011) and 
the educational field (e.g. Damanpour, 1987; Frank et al., 2004). Fewer empirical studies were conducted on social media implementation in libraries (e.g. Neo and Calvert, 2012). This empirical base needs to be expanded to cover more diverse organizations and to allow for more generalizable findings. As public (non-profit) organizations, libraries have many characteristics analogous to hospitals and schools; however, they are sufficiently different in their impact on individual's life chances in order to permit credible generalization of findings of previous research within other organizations.

This paper first provides a theoretical framework, in which we integrate social network theory into a theoretical model of diffusion of innovation within organizations. We then use social network analysis (SNA) to empirically assess how a social media expert in the library facilitates, or impedes, the information flow and implementation of social media. In the discussion, we review the findings, draw implications for social media experts in libraries, and identify limitations.

\section{Social network theory and the diffusion of innovations within the library}

According to Rogers $(1995,137)$, the four elements in any diffusion event are, “(1) an innovation, idea perceived as new by the potential adopting unit, (2) which is communicated through channels, (3) over time, (4) among members of a social system." This diffusion process involves a few members' individual knowledge of an innovation and their decision to adopt (or reject) this innovation, thus over time more individuals adopt the innovation until it is implemented into the organization (Valente, 1996). Nevertheless, the question remains how this idea of diffusion of innovation can be applied to organizations such as a library.

Initially, research on the diffusion of innovations focused on the individual as the unit of analysis (Rogers, 1995). It was assumed that if the individual is the unit who adopts or 
rejects the innovation, he or she must also be the unit of analysis (Coleman, 1958). This approach can easily be applied to strict hierarchical manufacturing organizations, but not to libraries where the decision-making process is more complex. In libraries, every individual has the autonomy to decide whether to adopt or reject an innovation, partly based on their knowledge they retrieve through contacts with others. Rogers (1995) suggests a social network approach to study the diffusion of innovations, which focuses on the unique interactions and exchange of resources between individuals. Wellman and Berkowitz (1988) argue that behavior is more affected by the kinds of relationships between people and the resources that are exchanged in the relationships than by the norms and attributes of individuals. In this study, we focus on social media information exchange as a resource.

Frank et al. (2004) have modified the social network approach to social processes that apply to members of an organization, which emphasizes two characteristics of an organization: social pressure and informal help. Organizations provide important advantages to their members regarding knowledge, social and psychological rewards, access to resources, and in some cases, even status. Therefore, it is possible that individuals within an organization apply social pressure to reward appropriate, and punish inappropriate, behavior. Thus, social pressure can be used by members of an organization to direct other members to support, or reject, an innovation, and to motivate them to achieve a common goal. Nevertheless, the management is of course expected to build an organizational strategy and common goal for using a new technology. However, much input still comes from informal interactions between team members (Frank et al., 2004). Explicitly on the implementation of a new technology within an organization, Gallivan et al. (2005) found that informal information sharing of coworkers has an important influence on employee's IT usage, while training organized by the management exhibits more modest effects. 
Social pressure and the exchange of informal help between members of an organization can be combined under the general theoretical framework of 'social capital'. This elastic term is used in multiple fields, each foregrounding a different aspect of the concept and offering a nuanced understanding of the idea (Bourdieu, 1986; Putnam, 1993). According to Lin $(2001,24)$, the common element between all theorists includes the understanding of social capital as: "the resources embedded in social relations and social structure, which can be mobilized when an actor wishes to increase likelihood of success in purposive action." Social capital has also been recognized as an important factor in the acceptance and use of information and communication technologies (ICT) (Korupp and Szydlik, 2005; van Dijk, 2005). On an individual level, this social capital can be thought of as "local experts" or "individuals who play a key role in the support of ICT adoption and use within a heterogeneous social network." (Stewart 2007, 551) More concretely, Bakardijeva $(2005,99)$ refers to them as "warm experts" or an "internet/computer technology expert in the professional sense or simply in a relative sense compared with the less knowledgeable other."

In the network literature, experts are referred to as the persons who are able to maintain, create or prevent the information flow (Frambach and Schillewaert, 2002; Haythornthwaite, 1996). Hence, we expect that social media experts (cfr. informal help) in the library as an organization can stimulate (cfr. social pressure), or impede, the exchange of information about social media between colleagues. Previous studies point out a number of indicators that can facilitate or impede the exchange of information from an expert within an organization, including the place of the expert within the network and the quality of ties between the expert and other members of the organization.

In addition to the presence of an expert, network structures may also support the exchange of information if the necessary relations or ties exist, but they may also limit 
resources transfers if the network does not hold sufficient or 'right' ties (Daly and Finnigan, 2010). Previous research indicates that if the actor in the information exchange network takes a central position, the more he or she can control the information exchange and consequently the implementation of an innovation (Haythornthwaite, 1996; Scott and Carrington, 2012). The people most central in an information exchange network are the experts or the ones who have the most knowledge and skills to be working on or near the core of the innovation within the organization (Frambach and Schillewaert, 2002). Hence, we wonder if the social media expert in the library takes the most central position in the information exchange network about social media, and consequently, gives the most information to other colleagues.

Although, the focus is on the role and position of a social media expert within the library as an organization, it is also important to include the quality of ties that exists between the expert and the other colleagues (Putnam, 1993). The quality of ties can be compared with the concept of 'tie strength' of Haythornthwaite (1996), which is considered as closeness between ties. The closer the actors are and the more reciprocal the relations are, the stronger the ties between the actors. Strong social ties have long been considered the most beneficial for information exchange (Festinger et al., 1950). Individuals who are more closely tied to each other have a more intimate relationship, which makes it easier to exchange information.

However, Granovetter (1973) and Hansen (1999) challenged this notion that only strong ties are valuable for information exchange by indicating that strong social ties provide the transfer of tacit or complex knowledge, while weak social ties are better suited to transport simple or routine information. Within an organization, such as the library, individuals have more intense relations with some members of the organization and less intense relations with other members. Rainie and Wellman (2012) argue that this variation in relations leads to a different scope and depth, which makes the combination of strong and weak ties valuable for the decision to adopt or reject an innovation. For the implementation of social media in the 
library, both strong and weak ties are necessary as they facilitate access to the more basic technological information, or the so-called 'button knowledge' (van Deursen and van Dijk, 2010), and to the more advanced knowledge about, for example, the business models of certain social media (Share et al., 2004). Hence, we wonder if the social media expert within the library gives more complex and advanced information to colleagues with whom he or she shares a more intense relationship (e.g. strong ties) than with whom he or she shares a less intense relationship (e.g. weak ties)?

\section{Methodology}

\subsection{Context}

This study is part of a research project funded by the Flemish government that aims to give a social media program with the goal of increasing the social media knowledge and skills of librarians. From each public library in Flanders (Belgium's northern Dutch-speaking region), one or two librarians were invited to attend the intensive social media courses, after which they function as a social media expert within their organization. This study focuses on libraries because they were believed, through other research, to be attempting to implement social media (e.g. Casey and Sevastinuk, 2006; Linh, 2008). The study was conducted in three public libraries located in Flanders, which contributed to the social media program. These libraries were selected for their almost equal distribution of library staff and their urban area locations, which allow for some comparison. Using mixed method design with a combination of social network analysis and face-to-face interviews, this study aimed to better understand how a social media expert could support or impede the information flow and implementation of social media in the library. 


\subsection{Data collection and analysis}

\subsubsection{Social network data collection}

The survey for the social network analysis was constructed to examine five types of social relations regarding information exchange about social media in the library: (1) discussing work, (2) personal advice, (3) discussing work related use of social media, (4) discussing personal related use of social media, and (5) giving information about social media.

Discussing work contains the circulation of information and resources pertaining to the organizational goals. We asked the librarians with whom of their colleagues they discuss work related issues. Based on Ibarra (1993), we refer to this relation as the 'instrumental network'. Personal advice contains more affective emotions and implies a certain level of trust between the people involved in the relationship. Such a strong bond between colleagues is believed to facilitate information exchange (Granovetter, 1973). This relation is defined as the 'expressive network' (Ibarra, 1993) and was measured by asking the following question: 'Who do you go to for guidance or advice on more personal matters?'. To measure instrumental and expressive networks for social media related issues specifically, we respectively asked 'To whom do you go to discuss your work related use of social media?' and, 'To whom do you go to discuss your personal use of social media?' Central to this study is information sharing about social media between library staff. Giving information addresses the issue of 'who seeks out whom' for advice and thereby, in contrast to the previous types of instrumental and expressive networks related to social media issues, implies the exchange of knowledge, information, competencies, or expertise between the expert and the novice. We assessed this relationship by asking the respondents to whom they give information about social media. 
These five questions were included in the survey to assess social relationships and to map the social network between librarians. All these social networks are directed: either a relationship exists between two colleagues ' 1 ' or not ' 0 '. Respondents were provided with a library specific appendix that contained the names of the librarians and answered each social network question by indicating which coworker(s) they consider part of their social network as specified by the question. The respondents could answer with an unlimited number of colleagues. All library staff of the three libraries were asked to participate in the social network question in the survey. In library 1, 77 of the 121 employees (64\%) responded, 66 librarians (82\%) of library 2 participated in the survey, and in library 3,45 of the 49 librarians $(92 \%)$ responded to the survey. The librarian samples consisted of more than double females than males with an average age between 44 and 49 years (library 1: Mage= 49.01SDage= $8.72,69 \%$ female $31 \%$ male; library 2 : Mage $=47.45$ SDage $=16.22,76 \%$ female $24 \%$ male; library 3: Mage $=44.74$ SDage $=9.31,77 \%$ female $33 \%$ male $)$.

The survey also included SML questions. To explore how well the library staff deals with social media, we conducted a cluster analysis on the SML questions. A magnification of the sample from three to six libraries was necessary to adequately perform this analysis. In total, 220 librarians participated in the survey, which is a response rate of $77 \%$. The SML survey contains questions to librarians' regarding, (1) social media use, (2) social media knowledge, and (3) technical, (4) cognitive, and (5) affective competencies.

Social media use was measured by asking the respondents how often they connect to social media during their work and leisure time. Responses were measured using a five-point scale ranging from 'never' to 'several times a day'. Technical and cognitive competencies were determined by how well the respondents evaluated their performance of social media activities. Simultaneously, we took into account the frequency of use of these activities. 
Hence, higher self-efficacy in performing these activities and more frequent usage was correlated to more advanced technical and cognitive competencies. We multiplied the selfefficacy measure with the frequency measure and treated the outcome as one variable. Exploratory factor analysis (maximum-likelihood estimation with varimax rotation) revealed two factors, which we labeled as 'technical competencies' on the one hand, and 'cognitive competencies' on the other hand. The technical competence scale consists of nine items $(\alpha=$ 0.94). With these technical competencies, we refer to, for instance, being able to upload pictures, tagging photos, and making comments on social media. The cognitive competence scale contains four items $(\alpha=0.91)$ related to, for instance, checking if the information in a social media message is still up-to-date, thinking about the context wherein content on social media is produced and evaluating whether the information on social media is correct or useful. Related to these technical competencies and cognitive competencies, which focus on skills, we also considered a measure of social media knowledge. Based on Hargittai (2009), we asked the respondents about their familiarity with certain terms related to social media use such as tagging, cookies, and social bookmarking. Responses were measured using 'yes' or 'no' answers. Raw scores consisting of higher values were taken to indicate a higher level of social media knowledge. We also measured affective competencies or attitudes based on a series of six items proposed by Bruner et al. (2001). The measure of attitudes contains an established six-item, seven-point semantic differential scale (bad/good, foolish/clever, unpleasant/pleasant, useless/useful, boring/interesting, and negative/positive). Factor analysis (varimax rotation) revealed a single factor, which we named social media attitudes $(\alpha=0.94)$. Raw scores consisting of higher values were taken to indicate positive attitudes towards social media. 


\subsubsection{Social network data analysis}

Network analysis identifies the communication structure, in this case, the information flow around social media in an organization (Rogers, 1995). These communication flows were analyzed using the above-mentioned interpersonal relationships as the units of analysis. A member of an organization is likely to communicate, in this case, about social media, with certain other members and pay little attention to other members. Social network analysis describes these linkages between individuals by plotting them in a 'whom-to-whom' communication matrix (Scott and Carrington, 2012). The matrix is constructed following the same procedure; if person A selected person B as a person to whom he or she gives social media information, for example, a 1 was entered in cell AB. A symmetric matrix contains data for an undirected network, while an asymmetric matrix records the direction of ties. In this study, we use an asymmetric matrix because giving social media information to another person does not automatically mean that information is also received.

To better understand the role of a social media expert in the information network about social media, we calculated several social network properties at both organizational and individual levels using the UCINET 6.0 software package (Borgatti et al., 2002). For this study, we focus on the social network properties listed below in this section, as they are the most relevant and explicit regarding how social media information circulates between librarians.

Organizational level measures include density, reciprocity, and mean degree centrality. Density can be interpreted as the concentration of relationships in a network and is calculated by dividing the number of actual relationships by the number of total possible relationships (Hanneman and Riddle, 2005). For example, the more relationships there are between the librarians concerning exchanging social media information, the more dense the social 
network. The density scores range from 0 (no relationship exists) to 1 (all members are connected to all other members). A dense network allows information to flow more quickly and freely than a network with fewer ties (Scott and Carrington, 2012).

Reciprocity examines the extent to which the relationships in a social network are reciprocal. For example, A nominates B as a person to whom he or she gives social media information and B nominates A. This property is calculated by dividing the actual number of reciprocal relationships by the total possible number of reciprocal relationships (Hanneman and Riddle, 2005). Previous research indicated that higher levels of network reciprocity are linked with a higher level of complex information exchange (Kilduff and Tsai, 2003). This reciprocity measure ranges from 0 (none of the relations are reciprocal) to 1 (all of the relations are reciprocal).

The mean degree centrality of the network is calculated by dividing the sum of the degree centrality of all the nodes in the network by the total number of nodes (Kretschmer and Aguillo, 2004). Although density is a better measure for understanding communication in a network as a whole, the measure of the mean degree centrality can compare individual scores of actors in relation to the network. This score can be compared with the in- and out-degree (see below) scores at the individual level.

At individual level, we calculated the raw and normalized scores for in-degree and out-degree (Hanneman and Riddle, 2005). In-degree reflects the number of people by whom a respondent was nominated and can consequently be interpreted as a measure for individual popularity. Out-degree represents the number of people nominated by the respondent and can therefore be seen as a measure of individual activity. While raw scores encompassed the actual numbers of respondents that were selected, normalized scores present the percentage of relationships of the whole network that respondents maintain. 
We also estimated a series of ANOVA Density Models (Hanneman and Riddle, 2005) to examine how members of a group relate to members of other groups. In our study, groups are defined according to individuals' social media expertise within the group. It is possible that social media experts prefer to have ties either with other experts in the library or with people who use social media less often. The ANOVA Density Models enable detection of differences within and between group ties. This measure gives the probability that a group is tied to another group; however, it does not specify in what way they differ.

To examine whether social media experts give more or less information about social media to people with whom they share a more or less intensive relationship (e.g. strong ties versus weak ties), a series of Quadratic Assignment Procedure (QAP) correlations in UCINET were estimated (Borgatti et al., 2002). The statistical technique of Pearson correlation is not relevant in this study because social relations between people are nested and embedded within the same network, which therefore violates the assumption of interdependence, whereas the QAP is designed for correlational analysis for social network data. A low proportion $(\mathrm{p}<0,05)$ indicates a strong correlation between the different kinds of social relations that are unlikely to have occurred by chance (Baker and Hubert, 1981).

\subsubsection{Collection of interview data}

The aim of the qualitative stage was to gather richer data to allow deeper insights into how social media experts reflect on the information flow of social media in the library. We conducted two hour-long face-to-face interviews with the five the social media experts Elena (library 1, age $=31$, profile $=$ social media literate), Lisa (library 1, 38, social media literate), Sophie (library 2, 35, social media worker), Paul (library 3, 32, social media literate), and Nina (library 3, 43, social media literate). As the interviewees were recruited out of the respondents who participated in the survey, we already had much (descriptive) knowledge 
about them. Furthermore, the respondents for this qualitative stage were 'purposefully' sampled based on the criteria of having social media expertise and their participation in the workshops. The interviews were audio-recorded and transcribed, and the data analyzed using the constant comparison technique with the help of NVivo 10. To obtain an overall sense of the interview data, we first read the full interview transcriptions. Next, we analyzed the data using an open coding procedure to realize a code list focused on giving social media information and the social media experts' role and position in the library. Then, we recoded the data in terms of categories provided by the literature review. For the data analysis, the real names of the interviewees were replaced with pseudonyms.

\section{Results: Access to expertise through help and talk.}

\subsection{Social media literacy profiles}

To detect SML profiles, a k-means cluster analysis was conducted on the five SML questions, and to identify the appropriate number of clusters $(\mathrm{k})$, we first conducted a hierarchical cluster analysis on the SML factors. Examination of the dendrogram revealed peaks at four and five clusters. A k-means cluster analysis was then conducted, examining four and five cluster solutions. Our typology containing four clusters was the most information-rich and interpretable. Table 1 provides an overview of these four clusters and their main characteristics.

The first profile, namely the 'Social media workers', contains those librarians who use social media the most in the library and have a relatively high level of SML. 'Social media laggards' do not frequently use social media either at home or at work and have a low level of SML. The 'social media literates' are the librarians who frequently use social media both at home and at work and have a high level of SML. Finally, the 'social media spare time users' are the librarians, who frequently use social media at home, but not in the library, and have an 
average level of SML. As expected, the social media experts belong to the group of social media literates and social media workers, who serve as facilitators or agents and can guide and support other librarians during the process of implementing social media in their organizations.

\section{TABLE 1 IS ABOUT HERE}

\subsection{The library and the information network about social media}

Table 2 indicates that all three libraries had a low network density score for sharing social media information. In other words, in these libraries $4 \%$ or less of all possible relationships formed around giving social media information are actually reported to exist. Nina (Library 3) gives the following reason for this low density score:

"For only a limited group of librarians, using social media is part of their job description. The other librarians do not have enough time or are not interested enough in social media to think or talk about social media in the library."

Library network level reciprocity of the information flow about social media varies among the libraries between 0.15 and 0.40 . This means that $40 \%$ and $15 \%$ of all relationships in libraries 2 and 3, respectively, are reportedly based on sharing mutual social media information. In library $127 \%$ of all relationships are reciprocal. Since previous research already indicated that higher levels of network reciprocity are linked with higher levels of complex information exchange (Kilduff and Tsai, 2003), we can assume that library 2 is the most effective and efficient at transmitting complex social media information. In contrast to the other libraries, librarians in library 2 , who professionally work with social media, sit on the same floor, and share much social media information; thus, other librarians who sit on this floor but do not professionally work with social media are also stimulated to discuss social media use. 
In libraries 1 and 3, social media information mostly stays within the group of the social media literates; therefore, we wondered whether we would also see this trend in the centrality measures. First, we discussed the distribution of the actor's degree centrality. On average, library 1, 2 and 3 have a degree of respectively 1.90, 1.81, and 1.78, which is quite low, given that there are 45 people or more in the libraries. We notice that the variation of out-degree is larger than that of in-degree suggesting that the population is more homogeneous with regard to in-degree than out-degree. This result is supported by the statements of Lisa, Elena, Sophie, and Paul in the interviews, who indicated that information about social media is mostly exchanged and discussed with people who are also skilled in social media. Lisa and Elena specify that in library 1:

"There is a social media working group, which consists of people who have the knowledge and skills to deal with social media and who are highly engaged with social media in their private lives. Information about social media is mostly exchanged within this working group."

\section{TABLE 2 IS ABOUT HERE}

\subsection{Social media experts as central actors}

We used Freeman's approach to measure the centrality of the social media expert(s) in the library network of giving social media information (Hanneman and Riddle, 2005). This approach measures the centrality of actors based on their out-degree and in-degree. Findings indicate that social media experts' have a similar position in all libraries; they are nominated as the person who gives the most information about social media and is consequently the most central; furthermore, they usually give more information about social media than they receive. Table 3 indicates that the social media expert with the highest out-degree gives social media information to $44 \%$ of her colleagues and receives information from only $5 \%$ of her 
colleagues. The normalized scores of the other social media experts reflect this pattern.

Except for Sophie and Nina, these social media experts have the lowest out-degree centrality, and give and receive social media information to only $9 \%$ and $11 \%$ of the colleagues, respectively. Both Sophie and Nina indicated in the interviews that social media does not belong to their job description and some of their colleagues have more knowledge and skills to deal with social media. Hence, Sophie and Nina also receive social media information from other social media literates in the library. This result is closely linked to the high score of library 2 on reciprocity. At library 3, the score on reciprocity is compensated by the low score on in-degree of the other expert in this library, namely Paul.

In contrast, as Elena and Paul have the greatest out-degrees, they might be regarded as the most powerful and influential concerning giving social media information. Both Elena and Paul explain this by the fact that colleagues not only ask them questions, but they sometimes also interfere when they hear someone talking to others about social media.

During the interviews, all social media experts revealed that they are the central point for questions on social media. Elena gives the following reasons for this social media responsibility:

\author{
"Because I used a lot of social media in my private life, and consequently have the \\ knowledge and skills. Probably also because I participated in the workshops about \\ social media. Because of these workshops, a lot of colleagues know that I have enough \\ expertise about social media."
}

These reasons mirror responses by the other social media experts regarding their central position in the social media information network.

TABLE 3 IS ABOUT HERE 


\subsection{The information flow about social media}

Social media experts are the primary conduits through which social media information is diffused. However, as it is not yet clear to whom they give information, we investigated who of the four SML profiles give social media information to each other using the ANOVA Density models.

In library 1 , the differences between the four profiles explain $10 \%$ of the variance in giving social media information. The ANOVA density models show that in library 1, social media literates give most information to other social media literates, who give less or no information to other profiles. In the interviews, the social media experts indicated that they tried to engage the less advanced social media users through workshops and courses.

However, only colleagues interested in social media participated in these courses. No other profiles give social media information to social media literates. In library 1, social media information remains within the group of social media literates, despite the numerous attempts of the social media experts to share information. This is confirmed by the statements of Elena and Lisa indicating that social media is mainly discussed in the social media working group.

For library 2 , only $2 \%$ of the variance in sharing social media information is explained by the differences between SML profiles despite all profiles in library 2 giving information to almost all other profiles. In the interviews, Sophie highlights that all librarians, not only those with more expertise, are responsible exchanging social media information with the youth section in the library. However, she admits that:

"It is easier to talk to people who know a lot about social media or frequently use social media in their private lives." 
In library 2, information does not remain within the social media literates group; however, most social media information is exchanged between social media literates and social media workers because the social media expert in this library belongs to the profile of social media workers.

In library 3 , almost $11 \%$ of the variance in sharing social media information is explained by the variations in SML profiles. Again, because social media literates give most information to other social media literates, most social media information remains within the group. However, they also give social media information to social media spare time users and workers and to a lesser extent to social media laggards, because of the disinterest or negative attitudes of the latter group towards social media.

Overall, social media laggards do not receive much social media information in the libraries despite their need for more information, because of their low level of knowledge and skills to deal with social media and their disinterest or negative attitude towards it. Social media experts, such as Lisa and Sophie, found it particularly difficult to give social media information to colleagues who do not use and/or are not interested in social media. In all three libraries, social media literates give most information to other social media literates. In library 1 , social media information is usually limited to the groups of social media literates or the experts, while in the other two libraries the information is also transmitted to other SML profiles. This finding about libraries 2 and 3 is congruent with the out-degree measures of the social media experts in these libraries.

\subsection{Social capital and librarians' development of social media literacy}

To understand whether social media experts only give advice about social media to the people they share an affective relation (i.e. expressive network) with or only give advice with whom 
they share a professional-related relationship (i.e. instrumental network), we made use of a QAP analysis.

Table 4 summarizes the QAP correlations between the instrumental and expressive social networks and the network of giving social media information. Overall, the results indicate that these networks weakly to moderately correlate in all libraries. Hence, librarians tend to maintain different networks for different purposes.

The correlations between giving social media information and the instrumental and expressive networks for social media are higher than those with the instrumental and expressive network in general. Paul, for example, indicated in the interviews that if colleagues discuss social media use for professional purposes in a meeting, social media experts are asked for advice. However, the correlations between giving social media information and the expressive social networks for social media are higher than the correlation between giving information and instrumental social networks for social media. This may be a first indication of a distinction between social networks that are specifically aimed at work (instrumental social networks) and social networks with a more affective connotation (expressive social networks). Librarians who discuss their private social media use are also more likely to share social media information with each other.

\section{TABLE 4 IS ABOUT HERE}

\section{Conclusion and discussion}

This paper examined how social media experts in libraries can support or impede the information flow and implementation of social media in a library context. The findings suggest that such social media experts play a significant role in either supporting or constraining the information flow and implementation of social media. 


\subsection{In libraries, there is little communication about social media}

A few librarians share social media information with other librarians, but receive little information in return. Moreover, people who are already skilled in social media use mostly discuss social media information, except for library 2 , where $40 \%$ of the relations are reciprocal. The more relations the actors maintain and the more reciprocal these relations are, the stronger the ties between actors and the better the transfer of complex social media information (Haythornthwaite, 1996). Individuals in libraries 1 and 3 demonstrated relatively weak ties concerning social media information exchange, meaning that only basic information about social media (i.e. button knowledge) is exchanged. A possible explanation is that social media use only represents a small part of the library operation and consequently not all librarians are interested in using, or have enough time to use, social media in the library. Working in the same office can stimulate the information flow on social media (see library 2), but is not the only explanation. Furthermore, as social media is only recently being introduced in the library, it is only discussed in-depth by a selected group of advanced users.

\subsection{A social media expert plays an important role in the library for spreading information} about social media

Unsurprisingly, social media experts are the most central actors for giving social media information; they share more social media information with other librarians and rarely receive information in return. Any information they do receive mostly comes from a person skilled in social media use. The social media expert as the central actor in the information network has the power to facilitate or prevent information exchange about social media (Scott and Carrington, 2012).

\subsection{Information about social media stays in the group of advanced social media users}

As mentioned above, the social media expert gives the most social media information to other 
colleagues. However, in most cases this information is given to colleagues who are already conversant with social media, with the least amount of social media information given to social media laggards or people who are not skilled at using social media. Therefore, social media information spread by social media experts usually remains within a group of skilled users. The latter is certainly the case when advanced users create a social media working group. This finding supports the Matthew effect, whereby the 'rich get richer' (Helsper, 2012; van Dijk, 2005). This is problematic because implementation of social media in the library is only successful if the laggards are also able to use social media to perform their professional responsibilities of providing information services such as teaching library customers to read and write, providing digital media training, and coordinating public programs. We might expect that support from a social media expert would enhance all librarians' SML. However, access, skills, interests, and infrastructure represent costs and barriers; therefore, greater usage, activities, and benefits flow to those with greater resources and abilities (DiMaggio et al., 2004). In this respect, the social media expert constrains the information flow about social media to librarians who are not or less conversant with social media. Libraries need to bring the social media laggards to the center of the social media information flow by, for example, involving them in the formation of a social media policy and/ or a working group on social media.

\subsection{Validation of the instrumental vs. expressive distinction}

In general, both instrumental and expressive networks specifically for social media tend to show a small to moderate overlap regarding the relationships of giving social media information. The private and professional discussion of social media stimulates the exchange of information about social media more than instrumental and expressive networks overall. In other words, social media information is most often exchanged between librarians who also 
discuss their private use of social media. This finding confirms the hypothesis that a friendship relationship between colleagues is believed to facilitate information exchange (Granovetter, 1973).

\subsection{Relevance, limitations, and areas for further research}

This study contributes to media literacy and library literature by drawing on social network theory and social capital theory to understand how the position of a social media expert in the library facilitates or impedes the distribution of social media information. The presence of a social media expert facilitates the information flow about social media to other librarians, as he or she is the most important source for information about social media. However, at the same time, the expert impedes the information flow to all librarians as he or she gives most information to librarians who are already conversant with social media and/or with whom he or she shares a more close relationship (e.g. friendship).

The findings from this research can be used to establish a social media policy or to provide social media training. In addition, longitudinal research could also follow up on these findings to inquire if the social media expert evolves when social media is successfully implemented in the library. Such data is useful for library policymakers.

While the sample size was chosen to conduct a mixed methods study that would explore how the position of a social media expert in an organization such as the library facilitates or prevents the exchange of social media information, we acknowledge the need for large-scale empirical studies that can substantiate our findings in larger and more diverse samples. In addition, despite selecting the five social media experts we interviewed from a range of degrees of centrality, it would be better to select a representative sample of librarians for each library to obtain opinions from other librarians on the role and position of the social media expert, not only that of the social media expert him- or herself. By focusing the scope 
of this study on librarians, we may have under-represented the connections between the head of the library, the librarians, and policymakers or employees of the local government where the library is situated. This could provide us with information about the wider context in which the implementation of innovation in a library happens.

This study demonstrates the importance but also the limitations of a social media expert in a library. If scholars, practitioners, and policymakers are to embrace social networks as a valuable lens to uncover the potential of social media experts for the implementation of social media in the library, deepened insights into the elements that shape social relationships among librarians are needed. This paper takes the first step to understand the role and position of a social media expert in the library. Follow up research should scrutinize the circumstances that affect the pattern of exchanging social media information in libraries and its potential to successfully implement social media in libraries. 


\section{References}

Anttiroiko, A. and Savolainen, R. (2007), "New premises of public library strategies in the age of globalization", In Garten, E.D., Williams, D.E., et al. (Eds), Advances in library administration and organization, Elsevier, JAI Press, Amsterdam, pp. 61-81.

Atun, R.A., Kyratsis, I., et al. (2007), "Diffusion of complex health innovations-implementation of primary health care reforms in Bosnia and Herzegovina", Health Policy Plan, Vol. 22 No. 1, pp. 28-39.

Baker, F.B. and Hubert, L.J. (1981), "The analysis of social interaction data: A nonparametric technique", Sociological Methods Research, Vol. 9 No. 3, pp. 339-361.

Bechmann, A. and Lomborg, S. (2013), "Mapping actor roles in social media: Different perspectives on value creation in theories of user participation", New Media \& Society, Vol. 15 No. 5, pp. 765-781.

Borgatti, S.P., Everett, M.G., et al. (2002), Ucinet for Windows: Software for social network analysis, Analytic Technologies, Harvard.

Bourdieu, P. (1986), "The forms of capital", In Richardson, J.G. (Ed), Handbook of theory and research for the sociology of education, Greenwich Press, New York, pp. 241258.

Callahan, D.R. (1991), "The librarian as change agent in the diffusion of technological innovation", Electronic Library, Vol. 9 No. 1, pp. 13-15.

Casey, M.E. and Sevastinuk, L.C. (2006), "Library 2.0: Service for the next-generation library", Library Journal, Vol. 131 No. 14, pp. 40-42.

Coleman, J.S. (1958), "Relational analysis: A study of social organization with survey methods", Human Organization, Vol. 17 No. 4, pp. 28-36. 
Daly, A.J. and Finnigan, K.S. (2010), "A bridge between worlds: Understanding network structure to understand change strategy", Journal of Education Change, Vol. 11, pp. $111-138$.

Damanpour, F. (1987), "The adoption of technological administrative, and ancillary innovations: Impact of organizational factors", Journal of Management, Vol. 13 No. 4 , pp. 675-688.

DiMaggio, P., Hargittai, E., et al. (2004), "From unequal access to differentiated use: E literature review and agenda for research on digital inequality ", In Neckerman, K. (Ed), Social inequality, Russell Sage Foundation, New York, pp. 355-400.

Festinger, L., Schacter, S., et al. (1950), Social pressures in informal groups, Stanford University Press, Stanford.

Frambach, R.T. and Schillewaert, N. (2002), "Organizational innovation adoption: A multilevel framework of determinants and opportunities for future research", Journal of Business Research, Vol. 55 No. 2, pp. 163-176.

Frank, K.A., Zhao, Y., et al. (2004), "Social capital and the diffusion of innovations within organizations: The case of computer technology in schools", Sociology of Education, Vol. 77 April, pp. 148-171.

Gallivan, M.J., Spitler, V.K., et al. (2005), "Does information technology training really matter? A social information processing analysis of coworkers' influence on IT usage in the workplace", Journal of Management Information Systems, Vol. 22 No. 1, pp. 153-192.

Granovetter, M.S. (1973), "The strength of weak ties", American Journal of Sociology, Vol. 78 No. 6, pp. $1360-1380$.

Hanneman, R.A. and Riddle, M. (2005), Introduction to social network methods, University of California, Riverside. 
Hansen, M.T. (1999), "The search-transfer problem: The role of weak ties in sharing knowledge across organization subunits", Administrative Science Quarterly, Vol. 44 No. 1, pp. 82-111.

Haythornthwaite, C. (2005), "Social networks and internet connectivity effects", Information, Communication \& Society, Vol. 8 No. 2, pp. 125-147.

Helsper, E. (2012), "A corresponding fields model for the links between social and digital exclusion", Communication Theory, Vol. 22 No. 4, pp. 403-426.

Huvila, I., Holmberg, K., et al. (2013), "What is Librarian 2.0 - New competencies or interactive relations? A library professional viewpoint", Journal of Librarianship and Information Science, Vol. 45 No. 4.

Ibarra, H. (1993), "Personal networks of women and minorities in management - A conceptual framework", Academy of Management Journal, Vol. 18 No. 1, pp. 56-87.

Kilduff, M. and Tsai, W. (2003), Social networks and organizations, Sage, London.

Korupp, S.E. and Szydlik, M. (2005), "Causes and trends of the digital divide ", European Sociological Review, Vol. 21 No. 4, pp. 409-422.

Kretschmer, C. and Aguillo, I.F. (2004), "Visibility of collaboration on the Web", Scientometrics, Vol. 61 No. 3, pp. 405-426.

Lin, N. (2001), Social capital: A theory of social structure and action, Cambridge University Press, New York, NY.

Linh, N.C. (2008), "A survey of the application of web 2.0 in Australian university libraries", Library Hi Tech, Vol. 26 No. 4, pp. 630-653.

Neo, E. and Calvert, P. (2012), "Facebook and the diffusion of innovation in New Zealand public libraries", Journal of Librarianship and Information Science, Vol. 44 No. 4, pp. $227-237$.

Putnam, R.D. (1993), Making democracy work, Princeton University Press, Princeton, NJ. 
Rainie, L. and Wellman, B. (2012), Networked: The new social operating system, MIT Press, Cambridge, MA.

Rogers, E. (1995), Diffusion of innovations, Free Press, New York.

Scott, J. and Carrington, P.J. (2012), Social network analysis, Sage, London.

Share, J., Jolls, T., et al. (2004), Five key questions that can change the world, Center for Media Literacy, Santa Monica, CA.

Stewart, J. (2007), "Local experts in the domestication of information and communication technologies", Information, Communication \& Society, Vol. 10 No. 4, pp. 547-569.

Tichy, N.M., Tushman, M.L., et al. (1979), "Social network analysis for organizations", The Academy of Management Review, Vol. 4 No. 4, pp. 507-519.

Valente, T. (1996), "Network models of the diffusion of innovations", Computational \& Mathematical Organization Theory, Vol. 2 No. 2, pp. 163-164.

van Deursen, A. and van Dijk, J. (2010), "Measuring internet skills", International Journal of Human-Computer Interaction, Vol. 26 No. 10, pp. 891-916.

van Dijk, J. (2005), The deepening divide: Inequality in the information society, Sage, London.

Wellman, B. and Berkowitz, S.D. (1988), Social structures: E network approach, Cambridge University Press, Cambridge.

Williams, I. (2011), "Organizational readiness for innovation in health care: Some lessons from the recent literature", Health Services Management Research, Vol. 24 No. 4, pp. 213-308. 
Table 1. K-means cluster analysis on centered variables $(* p<0.05, * * *<0.001)$

\begin{tabular}{|c|c|c|c|c|c|c|}
\hline & $\begin{array}{c}\text { Worker } \\
(23.37 \%)\end{array}$ & $\begin{array}{l}\text { Laggard } \\
(23.91 \%)\end{array}$ & $\begin{array}{l}\text { Literate } \\
(28.26 \%)\end{array}$ & $\begin{array}{c}\text { Spare } \\
\text { time } \\
\text { user } \\
(\mathbf{2 4 . 4 6 \% )}) \\
\end{array}$ & $\begin{array}{c}\text { Mean } \\
\text { square } \\
\text { clusters }\end{array}$ & F-value \\
\hline Attitudes & 3.52 & 2.86 & 4.18 & 3.65 & 13.97 & $44.47 * * *$ \\
\hline Knowledge & 2.27 & 2.03 & 3.54 & 2.76 & 21.67 & $37.91 * * *$ \\
\hline $\begin{array}{c}\text { Use of social media: } \\
\text { at home }\end{array}$ & 3.49 & 1.43 & 4.83 & 4.33 & 103.26 & $187.79 * * *$ \\
\hline $\begin{array}{c}\text { Use of social media: } \\
\text { at work }\end{array}$ & 3.77 & 1.23 & 4.56 & 1.42 & 131.71 & $375.09 * * *$ \\
\hline $\begin{array}{l}\text { Technological } \\
\text { competence }\end{array}$ & 0.12 & 0.00 & 0.83 & 0.38 & 6.63 & $29.51 * * *$ \\
\hline $\begin{array}{l}\text { Cognitive } \\
\text { competence }\end{array}$ & 0.16 & 0.02 & 0.92 & 0.29 & 7.78 & $37.91 * * *$ \\
\hline
\end{tabular}


Table 2: Descriptive statistics of libraries 1, 2, and 3

\begin{tabular}{|c|c|c|c|c|c|c|}
\hline & \multicolumn{2}{|c|}{ Library 1} & \multicolumn{2}{|c|}{ Library 2} & \multicolumn{2}{|c|}{ Library 3} \\
\hline $\begin{array}{c}\text { Mean Density } \\
\text { (SD) }\end{array}$ & \multicolumn{2}{|c|}{$\begin{array}{l}0.02 \\
(0.16)\end{array}$} & \multicolumn{2}{|c|}{$\begin{array}{l}0.03 \\
(0.16)\end{array}$} & \multicolumn{2}{|c|}{$\begin{array}{l}0.04 \\
(0.20)\end{array}$} \\
\hline \multirow{2}{*}{$\begin{array}{l}\text { Reciprocity } \\
\text { (arc-based) }\end{array}$} & \multicolumn{2}{|c|}{0.27} & \multicolumn{2}{|c|}{0.40} & \multicolumn{2}{|c|}{0.15} \\
\hline & Raw & Normalized & Raw & Normalized & Raw & Normalized \\
\hline $\begin{array}{c}\text { Mean Degree } \\
\text { Centrality } \\
\text { (SD-Out; SD-In) }\end{array}$ & $\begin{array}{c}1.90 \\
(5.44 ; 1.85)\end{array}$ & $\begin{array}{c}2.50 \\
(7.16 ; 2.43)\end{array}$ & $\begin{array}{c}1.81 \\
(3.04 ; 2.00)\end{array}$ & $\begin{array}{c}2.74 \\
(4.61 ; 3.03)\end{array}$ & $\begin{array}{c}1.78 \\
(2.82 ; 1.91)\end{array}$ & $\begin{array}{c}4.04 \\
(6.41 ; 4.34)\end{array}$ \\
\hline
\end{tabular}

30

35

36

37

38

39

40

41

42

43

44

45

46

47

48

49

50

51

52

53

54

55

56

57

58

59

60 
1

2

3

4

5

6

7

8

9

10

11

12

13

14

15

16

17

18

19

20

21

22

23

24

25

26

27

28

29

30

31

32

33

34

35

36

37

38

39

40

41

42

43

44

45

46

47

48

49

50

51

52

53

54

55

56

57

58

59

60

Table 3: Descriptive statistics of the individual level network properties

\begin{tabular}{|c|c|c|c|c|c|}
\hline & & \multicolumn{2}{|c|}{ Raw } & \multicolumn{2}{|c|}{ Normalized } \\
\hline & & Out-Degree & In-Degree & Out-Degree & In-Degree \\
\hline \multirow{2}{*}{ Library 1} & Elena & 34 & 4 & 44.737 & 5.263 \\
\hline & Lisa & 15 & 7 & 19.737 & 9.211 \\
\hline Library 2 & Sophie & 6 & 6 & 9.091 & 9.091 \\
\hline \multirow{2}{*}{ Library 3} & Nina & 5 & 5 & 11.364 & 11.364 \\
\hline & Paul & 14 & 4 & 31.818 & 9.091 \\
\hline & & & & & \\
\hline
\end{tabular}


Table 4: Average QAP correlations between instrumental and expressive networks and the network of giving social media information $(* \mathrm{p}<0.05, * * *<0.001)$

\begin{tabular}{|c|c|c|c|c|}
\hline \multicolumn{5}{|c|}{ Giving information about social media correlated with ... } \\
\hline & $\begin{array}{c}\text { Expressive } \\
\text { social network }\end{array}$ & $\begin{array}{l}\text { Expressive social } \\
\text { network for social } \\
\text { media }\end{array}$ & $\begin{array}{l}\text { Instrumental } \\
\text { social network }\end{array}$ & $\begin{array}{c}\text { Instrumental } \\
\text { social network for } \\
\text { social media }\end{array}$ \\
\hline Library 1 & $0.122 * * *$ & $0.397 * * *$ & $0.222 * * *$ & $0.276^{* * *}$ \\
\hline Library 2 & $0.181 * * *$ & $0.280 * * *$ & $0.155 * * *$ & $0.234 * * *$ \\
\hline Library 3 & $0.168 * * *$ & $0.207 * * *$ & $0.186 * * *$ & $0.164 * * *$ \\
\hline
\end{tabular}

